\title{
A lavoura canavieira em São Paulo. Expansão e declínio (1765-1851): um clássico da historiografia brasileira da década de 1960?
}

\begin{abstract}
Resumo
Não faz muito tempo que Maria Thereza Schorer Petrone nos deixou. O mais importante legado da historiadora pode ser aferido em uma obra consistente, competente quanto à investigação documental, verdadeira análise pioneira, datada dos idos da década de 1960, sobre a história de São Paulo. O lugar relevante que Petrone merece ocupar na historiografia brasileira advém, principalmente, da publicação de A lavoura canavieira em São Paulo. Expansão e declínio (1765-1851). Editado em 1968, o estudo tangencia discussões que guiariam o interesse dos historiadores quanto a renovadas possibilidades de análise durante as décadas seguintes. Por seu intermédio, desvenda-se a importância da lavoura açucareira nos cenários da economia e da sociedade paulistas da segunda metade do século XVIII e da primeira metade do século seguinte. É inegável que a análise, mediante sua riqueza de conteúdo, contempla, ainda nestes anos 2000, os interessados na história do açúcar paulista. Por demais interessante é a conclusão de Petrone no sentido de que o aumento significativo da produção de açúcar transformou, com suas fazendas e engenhos, parte do litoral paulista, assim como parte das terras ditas de serra acima. Ao mostrar como essas regiões acabaram por se tornar território dos canaviais, a autora revela que a exportação de açúcar foi responsável por inserir São Paulo no mercado internacional e por criar importante infraestrutura para o desenvolvimento da economia cafeeira, em torno da qual se organizou, de fato, a aristocracia agrária paulista. Estudo inédito digno, ainda hoje, de ser apreciado e/ou reapreciado, argumento central das reflexões que se seguem.
\end{abstract}

Palavras-chave: Brasil - Historiografia - Séc. XX. Petrone, Maria Thereza Schorer. Cana-de-açúcar - São Paulo (Estado) - História.

\author{
Esmeralda Blanco B. de Moura \\ Doutora em História Econômica pela \\ Universidade de São Paulo (USP). \\ Professora aposentada da Universidade \\ de São Paulo (USP) e orientadora de \\ Mestrado e de Doutorado do Programa \\ de Pós-Graduação em História \\ Econômica da mesma instituição. \\ São Paulo, SP- BRASIL \\ esmeraldamoura@usp.br \\ orcid.org/0000-0001-8920-2079
}

\section{Para citar este ensaio:}

MOURA, Esmeralda Blanco B. de. A lavoura canavieira em São Paulo. Expansão e declínio (1765-1851): um clássico da historiografia brasileira da década de 1960? Tempo e

Argumento, Florianópolis, v. 11, n. 28, p. 503 - 527, maio/ago. 2019. Ensaio. 


\title{
The sugar cane plantation in São Paulo. Expansion and decline (1765- 1851): a classic of Brazilian historiography of the 1960s?
}

\begin{abstract}
Not so long ago, Maria Thereza Schorer Petrone left us. Her most important legacy is a consistent, competent work on documentary research and more than that, a pioneering analysis, dating back to the 1960s, on the history of São Paulo. The relevant place that she deserves to occupy in Brazilian historiography comes mainly from the publication of $A$ lavoura canavieira em São Paulo. Expansão $e$ declínio (1765-1851). Edited in 1968, the study touches on discussions that would guide historians' interest in renewed possibilities of analysis over the following decades. Through it, the importance of sugar plantation is revealed in the scenarios of the economy and society of São Paulo in the second half of the eighteen century and in the first half of the following century. It is undeniable that the analysis, through its richness of content contemplates, still in early 2000, those interested in the history of sugar in São Paulo. Even more interesting from Petrone's conclusions is that the significant increase of the sugar production are transformed, with her farms and sugar mills, part of the coastal and interior regions. By showing how this regions were turned into sugar territory, she shows that it was the sugar exportation responsible for inserting São Paulo in the international market and for creating important infrastructure for the development of the coffee economy, around which the local agrarian aristocracy was, in fact, to be organized. Unprecedented study worthy, even today, to be appreciated and/or reappreciated, central argument of the following reflections.
\end{abstract}

Keywords: Brazil - Historiography - XX Century - Petrone, Maria Thereza Schorer - Sugar cane plantation - São Paulo (State) History. 


\section{Palavras introdutórias sobre a obra e sua autora, Maria Thereza Schorer}

\section{Petrone}

A historiografia construída décadas atrás - mediante percursos teóricometodológicos que, por vezes, viriam a ser revistos, rediscutidos e mesmo contestados, apoiada em fontes às quais outras se somariam ao longo do tempo, dando ensejo a novas interpretações, requer, ainda hoje, um olhar atento dos pesquisadores.

Não tem sido incomum endereçar aos estudos históricos antecessores das tendências historiográficas, que emergiram nas décadas finais do século XX e iniciais deste século, um olhar que os vê como silenciados no passado, fechados em si mesmos, como se nada mais tivessem a nos dizer. No entanto, o silêncio pode ser rompido e a oclusão - se é que existe - pode ser superada mediante um olhar renovado que os situe em sua própria historicidade, atento, portanto, aos liames que os põem em contato com as atualidades - sim, no plural - que os sucederam. No plural porque, em sua dinâmica, a história põe e repõe atualidades, as transformações, sejam de que natureza forem, processando-se com maior ou menor intensidade no decorrer do tempo, o que faz cada momento ser, de algum modo e, em certa medida, inusitado. O mesmo ocorre com a historiografia, o que implica em considerar, como ressalta Silva, as "condições da produção histórica" e em relacionar a obra resultante "com o momento histórico em que [foi] produzida" (SILVA, 2001, p. 53). Em outras palavras, o historiador e, não somente ele, mas, também sua obra, devem ser considerados em sua própria contemporaneidade.

No trajeto de construção do conhecimento histórico, em constante renovação, suscetível a questionamentos, passível de reinterpretações, como manter no reduto do ultrapassado a historiografia que antecedeu as novas vertentes historiográficas? Impossível omitir o quanto os estudos históricos construídos no interregno entre a década de 1960 - década eleita aqui como referência por demarcar a publicação de $A$ lavoura canavieira... - e o emergir das novas tendências historiográficas marcou presença no aflorar de novas possibilidades de pesquisa, inspiradas, muitas vezes de permeio, por suas sugestões, por oposição ou não as suas assertivas e convicções.

Retomar os estudos históricos apontados acima, assim como estabelecer com eles um primeiro contato, ainda que décadas após sua publicação, pode conduzir à 
surpreendente descoberta de temáticas latentes no interior de análises dadas, a princípio, como lidas em definitivo porém, plenas de potencialidades. A rigor, possibilidades de pesquisa que, restritas à brevidade de argumentos, meramente pontuadas no fluir dos textos ou reduzidas a indícios em suas entrelinhas, demandaram tempo para ganhar expressão no recinto das discussões historiográficas ou permaneceram no aguardo de pesquisadores que por elas viessem a se interessar,não raro devido a dificuldades quanto à disponibilidade de fontes ou, simplesmente por não estar, sua abordagem, prevista dentre os objetivos do historiador.

A lavoura canavieira em São Paulo. Expansão e declínio (1765-1851), obra da autoria de Maria Thereza Schorer Petrone, docente do Departamento de História da Faculdade de Filosofia, Letras e Ciências Humanas da Universidade de São Paulo e orientadora junto ao Programa de Pós-Graduação em História Econômica nessa mesma instituição, no decorrer da segunda metade do século XX, é particularmente digna de ser reapreciada. Reapreciada e não simplesmente relida dada a forma como a percepção de sua autora revela-se apurada ao intuir temas, ao tangenciá-los no transcorrer da análise em meio à relevância que confere ao cultivo da cana e à produção de açúcar e de aguardente em terras paulistas tanto litorâneas, quanto interioranas. Percepção que a faz valorizar aspectos da economia açucareira capazes, respectivamente, de insinuar e de explicitar questões de fundo para o entendimento da história do setor primário da economia brasileira.

Tese de Doutorado defendida em 1964 na referida Faculdade, editada em 1968 pela Difusão Européia do Livro como volume XXI da coleção Corpo e Alma do Brasil, dirigida por Fernando Henrique Cardoso, a obra em questão proporciona, a quem se dedicar a sua leitura, para além dos aspectos atinentes ao cultivo da cana, à produção e comercialização do açúcar e de aguardente paulistas, um encontro, também, com o mundo do trabalho no campo durante a escravidão.

Entre os finais das décadas de 1960 e 1970, assim como no adentrar dos anos de 1980, outras publicações iriam referendar o interesse da historiadora em se voltar tanto para os latifúndios em São Paulo, quanto para os núcleos coloniais alicerçados na pequena propriedade e situados principalmente no Sul do país, sem jamais perder de 
vista as terras paulistas. Se, nas páginas de A lavoura canavieira..., os escravos muitas vezes se tornaram sobressalentes ao tema central da obra, a autora, invariavelmente atenta ao trabalho no campo, voltou-se, na sequência de suas investigações, para os trabalhadores livres e as direcionou para a segunda metade do século XIX e o alvorecer do século XX. Os imigrantes ascendem, então, ao primeiro plano da análise como sujeitos sociais aos quais estariam reservados destinos distintos conforme sua inserção como trabalhadores em grandes propriedades cafeicultoras ou como pequenos proprietários em núcleos coloniais, ainda que viessem, conforme esclarece a historiadora, a ser designados, na época, sempre como colonos (PETRONE, 1967). Percurso analítico esse, em que Petrone descortina a pobreza que os afligia na Europa e situa o quanto a "procura da terra era uma constante na tradição cultural de muitos imigrantes" (PETRONE, 1982, p. 52), a fomentar a disposição de deixar o país de origem, assim como o quanto a política imigratória fomentada por governantes brasileiros transformou essa esperança em recurso de propaganda eficaz sobre o Brasil. Esperança, de resto, alimentada por uns e outros, na esteira da importância econômica adquirida pelo cultivo do café no interior de São Paulo - portanto, não mais do açúcar - e de seu peso crescente na pauta das exportações brasileiras.

No que tange, em particular, à história do açúcar paulista, o empenho da historiadora ao garimpar documentos e com eles estabelecer um diálogo sem precedentes, tornou possível demonstrar o quanto a "importância da agricultura para o desenvolvimento da Capitania era (...) bem conhecida em 1800, época - como faz questão de lembrar - em que o sonho do ouro já se tinha acabado" (PETRONE, 1968, p. 15). Mais do que isso, tornou visíveis sujeitos sociais que, embora anônimos, lograram, por meio de sua sensibilidade como pesquisadora, conquistar um lugar no contexto da história da Capitania e, depois, Província de São Paulo.

Somadas, as obras de Maria Thereza Schorer Petrone configuram ampla abordagem sobre a História de São Paulo, não sem contemplar, em especial, o conjunto dos trabalhadores rurais e sua flagrante diversidade: escravos; trabalhadores livres em época de escravidão; o arrastar-se da transição para o trabalho livre; o advento da imigração massiva e da liberdade no mundo do trabalho. Trabalhadores situados, durante 
a escravidão e no pós-abolição, não somente à sombra da produção de açúcar, de café e da própria lavoura de mantimentos, mas, à luz de sua própria agência.

Ao direcionar seu interesse, em particular, para a produção agrária e os sujeitos sociais que transitaram no âmbito do trinômio terra, poder e trabalho, Petrone conduziu suas reflexões de modo a estabelecer firme conexão com as distintas dimensões da história. Com esse propósito fez, do trabalho e dos trabalhadores rurais, um ponto de convergência capaz de evidenciar, já na década de 1960, que a história econômica não implica, necessariamente, em uma abordagem hermética, de rígido caráter economicista; que é factível ir além da análise quantitativa e fazer prevalecer "a percepção mais ampla da economia, [mediante] perspectiva teórica permeável às manifestações sociais, políticas, culturais" (MOURA, 2006, p. 11).

\section{A lavoura canavieira...: um clássico sobre a história do açúcar paulista?}

Apreciar A lavoura canavieira... é estar diante do revelar-se da história do açúcar paulista por meio de investigação em documentos inéditos, de tipologia variada, manuscritos e impressos, do cuidadoso diálogo que a autora empreende com seus emissores, pesquisa minuciosa cuja densidade deixa perceber a inexistência, em plena década de 1960, de historiografia prévia a sua obra. Contudo, é interessante que esse propósito contemple, da mesma forma, as pesquisas que a sucederam ou, em outras palavras, o caminhar dos estudos históricos que, posteriormente, elegeriam temáticas às quais A lavoura canavieira... havia conferido visibilidade.

Devo ressaltar, entretanto, que o argumento de que se trata de leitura imprescindível, verdadeira referência para quem se interessa pela história agrária de São Paulo, não me parece capaz de justificar, a contento, a inserção da obra no rol dos clássicos da historiografia brasileira. Peço, então, licença aos editores de Italo Calvino: Por que ler os clássicos, para me apropriar, momentaneamente, da frase com que abrem a edição composta por dois ensaios do referido escritor, ensaios que situam no conjunto das mais importantes reflexões a que se devotou a humanidade: "Clássico é o livro que pode ser lido sempre" (CALVINO, 2009, p. 3). Resposta concisa, suficiente talvez, à indagação que acompanha o título deste texto. 
De todo modo, recorro à fascinante argumentação de Calvino, principalmente ao argumento central que acompanha sua definição do que é uma obra clássica, tessitura, passo a passo, da trama resistente capaz de sustentar textos que não se vergam frente à inexorável passagem do tempo: "É clássico aquilo que persiste como rumor mesmo onde predomina a atualidade mais incompatível" (CALVINO, 2009, p. 28). É certo que, ao fazêlo, não tenho em mente as obras nascidas da inspiração de Homero, Dostoievski, Rousseau e outros tantos autores, como os tem Calvino. Não obstante, ao focalizar A lavoura canavieira... através de suas lentes, encontro, em seus argumentos, convicções que me permitem considerar o livro como tal, um dentre eles definitivo, assim como o corolário em que se desdobra: "Toda releitura de um clássico é uma leitura de descoberta como a primeira" (CALVINO, 2009, p. 17), o que equivale a considerar que "Um clássico é um livro que nunca terminou de dizer aquilo que tinha para dizer" (CALVINO, 2009, p.18).

Essa perspectiva me faz acompanhar o pensamento de Calvino e deixar que a obra em questão possa, na medida do possível "falar sem intermediários" (CALVINO, 2009, p. 20), isto é, de modo apartado das críticas e comentários que eventualmente lhe foram tecidos na ocasião em que veio a público e na posteridade, assim como de prováveis resenhas que tenham acompanhado sua edição. Assinalo, porém, que o faço ciente da intermediação que posso vir a estabelecer entre a mesma e quem se dispuser a sua leitura a partir deste texto. Ciente, ademais, de que é suficiente abrir o livro para que leitores e leitoras se deparem com as palavras de Sérgio Buarque de Holanda ao Ihes apresentar a obra. Intermediação, essa, francamente disponível nas dobras de capa do livro e, vale notar, autorizada, por ter sido, o historiador, orientador de sua autora na qualidade de responsável, nos idos da década de 1960, pela então denominada cadeira de História da Civilização Brasileira da Universidade de São Paulo.

\section{A lavoura canavieira... sem intermediários: o que sua autora tem a nos dizer}

As páginas de A lavoura canavieira... abrem-se com a advertência de sua autora quanto a ser, a história do açúcar paulista, pouco conhecida devido à inexistência de estudos anteriores, em contraposição ao que ocorria, já nos anos de 1960, com outras áreas canavieiras do país. Não contarão, leitores e leitoras, portanto, com densas 
reflexões de caráter historiográfico que pudessem ter colocado à disposição de Maria Thereza Schorer Petrone, um ponto de partida. Se, desse modo, sua obra expressa um intenso diálogo com as fontes, deixa perceber, por outro lado, o quanto são restritas as possibilidades de empreender uma verdadeira interlocução com estudos direcionados para o cultivo da cana e a produção de açúcar em São Paulo.

Exceção feita a discordâncias com Gileno de Carli e com Caio Prado Júnior, a serem retomadas oportunamente, cujas obras foram publicadas respectivamente em 1943 e em 1945, a historiografia de meados do século XX coloca a autora na condição de construir o próprio percurso de investigação e análise sem possibilidades de retomar ou refazer, de fato, caminhos analíticos anteriores, porque praticamente inexistentes. Dentre os títulos que a historiadora aponta como referências bibliográficas são poucos os relativos à economia açucareira. Alguns, dentre eles, correspondem à produção no Nordeste brasileiro, sendo ainda menos expressiva a presença de títulos que dizem respeito, em particular, a estudos sobre o açúcar paulista.

As dificuldades com que a autora se depara não se restringem à historiografia, uma vez que a interlocução com as fontes é permeada por incertezas: estatísticas inexatas; falta de referências sobre a extensão das fazendas de cana; inexistência de números consistentes sobre os custos do transporte do açúcar até o porto de embarque do produto; distorções relativas aos dados de produção e/ou de exportação frente às exigências, por parte de autoridades, de informações com finalidade fiscal; dados de produção mesclados aos de exportação; a circunstância de que estes últimos, circunscritos ao porto de Santos, mostravam-se insuficientes para permitir avaliação mais precisa do montante de açúcar exportado; ausência de informações relativas à origem do capital investido na lavoura de cana--de-açúcar. Contingências que a fazem utilizar as informações como referências indicativas para compreender a dinâmica do plantio de cana, da produção e da comercialização do açúcar, da fabricação de aguardente em São Paulo, mas que não a impedem de acompanhar a expansão da lavoura canavieira nas distintas áreas sobre as quais avançou, os termos desse avanço e as particularidades que apresentou no litoral e nas regiões ditas de serra acima. 
No litoral paulista, principalmente na porção em que a faixa litorânea se espraia para o Norte, isto é, Ubatuba, São Sebastião - Vila Bela, a produção açucareira ganharia expressão ao final do século XVIII. Nas denominadas áreas de serra acima, a lavoura canavieira tornar-se-ia, nas palavras da própria autora, "uma atividade bastante lucrativa" (PETRONE, 1968, p. 38), mais precisamente, ao longo do caminho em direção ao Rio de Janeiro e na região do que se convencionou chamar de quadrilátero do açúcar, haja vista a fertilidade do solo do planalto paulista. Ângulos delimitados pelas cidades de Sorocaba, Piracicaba, Mogi-Guaçu e Jundiaí, a região do quadrilátero, cuja expansão ocorre na segunda metade do século XVIII e na primeira do século seguinte, tornar-se-ia, esclarece a autora, a "área de eleição da cana-de-açúcar" (PETRONE, 1968, p. 41), a requerer, portanto, análise mais detalhada. Ocasião em que expressa, em nota de rodapé, sua discordância em relação a Caio Prado Júnior que, em Formação do Brasil Contemporâneo, elege a cidade de Porto Feliz, e não a de Sorocaba, como um dos vértices a demarcar o quadrilátero (PRADO JÚNIOR, 1945, p. 75 apud PETRONE, 1968, p. 24).

Destarte, grande parte da análise encontra-se direcionada para essa área, as condições que apresenta, as possibilidades de organizar a infraestrutura requerida para a comercialização do açúcar, cuja cultura, após florescer na Baixada Santista no século XVI, estagnar e entrar em decadência, tornar-se-ia, em meados do século XVIII, verdadeiramente "insignificante" na avaliação da autora (PETRONE, 1968, p. 9). Sem desaparecer completamente, a cultura de cana, assim como a fabricação de açúcar e de aguardente, iriam readquirir importância econômica, em São Paulo, a partir do governo do Morgado de Mateus, Luiz Antonio de Souza Botelho Mourão. Governo cujo início, o ano de 1765, corresponde a uma das balizas temporais da autora e cuja vigência encerrase em 1775. A análise, no entanto, estende-se até 1851, conjuntura em que o café se sobrepõe ao açúcar no contexto da economia paulista.

A história sobre a qual a autora se debruça é complexa, requer o olhar criterioso do historiador, a interlocução cuidadosa com as fontes, o elucidar de questões que exigem percursos distintos de análise: as condições que favoreceram a lavoura canavieira em São Paulo; a relação entre disponibilidade de capital, expansão da área cultivada, métodos de cultivo e aumento da produção, assim como da população na trilha da 
economia açucareira e de seu crescimento; as técnicas de beneficiamento e fabricação de açúcar e, também, de aguardente; os aspectos referentes à mão de obra; o processo de comercialização e exportação do açúcar, de seu acondicionamento em cestos e acomodação em mulas, ao arriscado trajeto em demanda do porto de destino; a difícil jornada dos denominados condutores de açúcar - tropeiros, camaradas - ao longo dos caminhos sinuosos e precários a distanciá-los do porto de Santos; as dificuldades que enfrentavam durante o processo de comercialização do produto, tais como os prejuízos decorrentes de sua deterioração quando exposto às intempéries, os acidentes com mulas carregadas de açúcar nas encostas íngremes da Serra do Mar; as circunstâncias em que se encontravam as tropas ao desfrutar, nos ranchos, de alojamento, alimentos e merecido descanso; a conjuntura internacional que propiciou o desenvolvimento da economia açucareira em São Paulo e que, depois, iria compor o quadro em que a mesma perderia expressão na pauta brasileira de exportações.

Ao se voltar para as fazendas de cana-de-açúcar, cuja origem vincula às sesmarias e sua subdivisão tanto mediante a venda, quanto por meio de herança, a autora procura destrinchar os termos de ocupação das terras paulistas. Ocupação que, em virtude da demarcação precária das sesmarias, da inexistência de títulos que comprovassem posses, se vê permeada por conflitos entre aqueles que almejavam possuir as terras, bem como entre vizinhos, conflitos que repercutiriam no desenvolvimento da agricultura. Preocupada com as características e constantes transformações da rede fundiária ligada à lavoura de cana-de-açúcar, direciona a análise para os processos de fragmentação das fazendas e de formação de fazendas mediante a aglutinação de lotes. O cultivo das terras é dado a conhecer, no fluir de A lavoura canavieira...: cana em terras cultivadas "a favor", portanto, em terras alheias e a título gratuito; cana cultivada por proprietários de terras mas, que se viam na iminência de contar com engenhos vizinhos para sua moagem; foreiros que plantavam a cana e instalavam o engenho em terras aforadas e, portanto, mediante o pagamento de foro. A análise se faz não sem que a autora se mostre atenta a outras práticas econômicas, a um só tempo, tributárias da lavoura de cana-de-açúcar e indispensáveis aos seus desígnios, a cultura de mantimentos e a criação de gado (PETRONE, 1968, p. 54-55). Entrementes, a tentativa de estabelecer a origem do capital 
investido na economia canavieira paulista resulta, dada a já apontada ausência de informações, na suposição de que tenha sido proveniente em parte do comércio e, em escala reduzida, das minas.

Ao adentrar a fazenda canavieira, a autora acaba por desvendá-la como universo que não poderia conter apenas canaviais mas, que requeria grandes reservas de matas devido ao significativo consumo tanto de madeira, para construir e instalar o engenho, quanto de lenha para ativar suas fornalhas. Ao analisar as áreas de expansão da lavoura canavieira, se detém nos tipos de engenhos - moendas movidas por animais, engenhos d'água e mesmo engenhocas - os custos de sua construção, os requisitos para que pudessem ser instalados e para que a fazenda fosse, de fato, produtiva: disponibilidade de terras, de escravos, de água, de matas, de pastos, a existência de estradas ou de rios navegáveis, a proximidade de núcleos habitados que tornassem possível aos moradores da própria fazenda satisfazer as necessidades cotidianas, quer materiais, quer espirituais.

Nesse ínterim, coloca leitores e leitoras em contato com os tipos de cana, com o processo de beneficiamento e de fabricação não só de açúcar mas, também, de aguardente, assim como identifica, no interior da fazenda açucareira, canaviais e, por vezes, engenhos itinerantes em busca de terras novas, fosse para expandir a cultura principal, isto é, do próprio açúcar, fosse para garantir o cultivo dos imprescindíveis gêneros alimentícios. Momentos esses, ressalta, de abandonar periodicamente a terra às vezes por longos anos - para que pudesse descansar e recuperar a tão desejada fertilidade mediante o crescimento, depois derrubada e posterior queima da capoeira. Época, portanto, de desconhecimento de práticas tais como o uso do arado, a adubação e a rotação de culturas.

Na medida em que a análise prossegue, a historiadora demonstra, passo a passo, que São Paulo, reverenciado, ao longo de sua história, por seus cafezais e suas indústrias fora, em outros tempos, território dos canaviais. 


\section{São Paulo: território do café e, também, da cana-de-açúcar}

"Os traços deixados pelo café na paisagem paulista ainda são perceptíveis, ao passo que os do açúcar desapareceram" (PETRONE, 1968, p. 226). Assim Maria Thereza Schorer Petrone conclui a análise sobre a economia açucareira em São Paulo. Por mais que não se aplique, como afirma, estabelecer comparações entre o significado da canade-açúcar na Bahia ou em Pernambuco e seu significado em território paulista, sua análise é conduzida, passo a passo, no intuito de demonstrar a importância dessa cultura na história de São Paulo, de ter sido, por mais de meio século o produto-chave da economia paulista, no que é bem sucedida. É com pertinência, portanto, que refuta Carli em meio à restrita interlocução que Ihe é possível estabelecer com a historiografia referente ao açúcar paulista, historiografia, como afirmado acima, quase inexistente. Se esse autor, ao se voltar para o tema na década de 1940, na obra Gênese e Evolução da Indústria Açucareira de São Paulo, havia considerado que o açúcar não deixara vestígios na paisagem paulista (CARLI, 1943, p. 17 apud PETRONE, 1968, p. 225), Petrone assevera que "O engenho e o canavial [haviam impregnado] a paisagem transformando-a completamente" (PETRONE, 1968, p. 225). Constata, a autora, que a cana fora responsável por dar origem e desenvolver cidades, bairros e mesmo povoados inseridos na área do chamado quadrilátero, além de ter sido, o lucro que proporcionara, determinante para que os mesmos adquirissem importância gradativa em São Paulo.

No transcorrer da análise, a autora inclina-se sobre a agricultura em São Paulo para, igualmente, elucidar convergências entre os sinais de esgotamento da lavoura canavieira e os indícios de importância crescente da lavoura de café. Por demais interessante é a forma como pontua a lavoura cafeeira insinuando-se em meio às plantações de cana-de-açúcar, os dados sobre a produção de café projetando-se junto aos dados da produção açucareira e, finalmente, entre 1850 e 1851, o planalto, como afirma, a encontrar sua vocação no valioso grão em torno do qual iria se organizar, de fato, a aristocracia agrária paulista.

Ao finalizar a obra, mais do que concluir sobre a própria economia açucareira e as circunstâncias de seu declínio, Petrone resvala em verdadeira introdução à expansão da economia cafeeira em São Paulo. Comprova, em suma, o quanto a história do açúcar 
enreda-se à história do café, herdeiro que é este último, da infraestrutura econômica construção de estradas, aparelhamento, internacionalização e consequente monopólio do porto de Santos - que fora organizada com vistas a favorecer a expansão dos canaviais em solo paulista.

Em poucas palavras, no entendimento da autora, o açúcar fora capaz de inserir São Paulo no cenário da economia internacional. A agricultura tornara-se comercial, o sistema viário passara por transformações, dadas as dificuldades para transpor o trajeto entre áreas produtoras e o embarque do açúcar rumo aos países que o importavam; paisagens haviam sido definidas ou redefinidas por conta da fragmentação e aglutinação da rede fundiária, assim como em virtude da busca por matas e de sua derrubada. Recursos e circunstâncias capazes de incentivar o abandono da cultura de cana-de-açúcar, às voltas com dificuldades no mercado externo, e a opção pelo cultivo do café. Os cafezais não só prescindiam da exigência de fornalhas diuturnamente aquecidas e, portanto, da disponibilidade incessante de matas mas, haviam encontrado recursos prévios nas paragens de São Paulo, verdadeiros estímulos ao seu cultivo, além de contarem com circunstâncias internacionais favoráveis a sua comercialização. Traduzida em números na pauta das exportações nacionais, a produção de café acabou por suplantar, gradativamente, o desempenho do açúcar na balança comercial brasileira, produto, este último que, a partir de fins da década de 1840, perderia expressão no comércio da Província de São Paulo para, em 1850-1851, já não comparecer em primeiro lugar nas listas de exportações por Santos.

Por mais que a queda na produção de açúcar tenha preocupado as autoridades paulistas e sejam quais forem as razões que afetaram seu desempenho, o pessimismo que assombrara os homens públicos quanto às condições miseráveis da Capitania havia, ressalta a autora, desaparecido na esteira das plantações de cana. A cana-de-açúcar havia, enfim, inaugurado um novo tempo para a Província de São Paulo. No substrato de sua análise, Petrone situa o despontar da crença na viabilidade do progresso paulista, de suas manifestações iniciais, a acompanhar, de perto, a expansão da lavoura canavieira e a consequente inserção da economia açucareira no mercado externo. Superado o pessimismo, esclarece, a palavra decadência desapareceria dos documentos e, deixaria, 
enfim, de constar das vozes das autoridades em referências às perspectivas econômicas de São Paulo.

\section{Vislumbres das novas tendências historiográficas em A lavoura canavieira...}

Na seara dos estudos historiográficos, conte ou não com os ditos intermediários, é imprescindível que o pesquisador, ao construir sua própria análise, se volte para a historiografia que lhe é antecessora e considere a história das narrativas que a compõem para que não se veja, conforme alerta Silva, nas rédeas de "armadilha muito comum neste gênero de trabalho, [a de crer] que o objeto de sua pesquisa, que a estratégia que adotou e o conteúdo que veicula constituem a última palavra sobre a matéria em questão" (SILVA, 2001, p. 17).

Considero igualmente válido inverter o pensamento de Silva para lembrar outra armadilha também comum: a de que o pesquisador possa acreditar haver proferido a primeira palavra sobre a temática que elegeu na elaboração de sua obra, o que me faz retomar, uma vez mais, os argumentos de Calvino para com ele lembrar que "ler os clássicos é melhor do que não ler os clássicos" (CALVINO, 2009, p. 30).

Apreciar ou reapreciar A lavoura canavieira..., inteirar-se do conteúdo da obra sem perder de vista a produção historiográfica que a sucedeu, corresponde a um interessante exercício de flashback capaz de subverter possíveis indiferenças em relação às reflexões que contém, apesar de distantes no tempo. Não há como deixar de notar que a autora anuncia questões importantes sobre as quais os historiadores brasileiros mostrar-se-iam interessados nos anos imediatamente posteriores à referida publicação e no transcorrer das décadas que, a partir dos anos de 1970, dariam ensejo a novas abordagens historiográficas. Vislumbres de temas a partir do trato com a documentação, a sugerir possibilidades de pesquisa, a introduzir discussões historiográficas futuras. Temas ora pontuados, ora analisados apenas como subtemas constitutivos da análise mais abrangente, abordados, portanto, em que pese a rigorosa fundamentação por parte da autora, de modo menos aprofundado em relação ao mote principal de sua narrativa. 
A antecipar o que se convencionou chamar, na proximidade dos anos 2000, de História Ambiental, a autora estabelece a relação entre a expansão da lavoura de cana-deaçúcar e a questão do desaparecimento e preservação das matas em São Paulo. O ponto de partida nesse quesito está no reconhecimento de que a fazenda de cana, conforme anteriormente pontuado, "não podia conter apenas canaviais" mas, exigia "uma área de mata [a eles] proporcional" (PETRONE, 1968, p. 78). Matas, com vistas a prover os engenhos de lenha e para abrigar, após a derrubada e a queimada, a lavoura principal, pastos e a cultura de mantimentos - feijão, milho, dentre outros - necessários para alimentar o pessoal das fazendas.

Afirma a autora que, encerrada a fase áurea do açúcar, São Paulo ainda contava com grandes reservas de matas, o que não impedia que sua devastação fosse notada. $O$ governo e, da mesma forma, os habitantes, haviam começado a se preocupar, já ao final do século XVIII, com sua derrubada constante, haja vista a Carta Régia de 1797 determinar que as localizadas no litoral e nas margens dos rios passavam a ser de propriedade da Coroa. Dentre outros documentos em que essa preocupação transparece, a autora coloca leitores e leitoras em contato com correspondência do governador Melo Castro e Mendonça endereçada, em 1798, ao Tribunal do Conselho Ultramarino, atento ao desamparo que ameaçava os engenhos na iminência da falta de lenha para alimentar as fornalhas, o prejuízo que rondava a vida do "Lavrador [ao se ver] sem Mattas" (Documentos Interessantes para a História e Costumes de São Paulo, 29, p. 74 a 79, carta de Mello Castro e Mendonça ao Tribunal do Conselho Ultramarino de 15 de novembro de 1798, apud PETRONE, 1968, p. 81). Manifestação seguida de outra, contida em narrativa de José Bonifácio de Andrada e Silva que, em 1820, no trajeto de Parnaíba a Itu por ocasião de sua Viagem Mineralógica na Província de São Paulo relata que "as antigas matas [haviam sido] barbaramente destruídas com o fogo e o machado", pois "não se [sabia] cultivar" sem devastar a paisagem (SILVA, José Bonifácio de Andrada e; (e) ANDRADA, Martim Francisco Ribeiro de, Viagem Mineralogica na Provincia de São Paulo. Boletim Paulista de Geografia, 17, p. 55, apud PETRONE, 1968, p. 82).

Desse modo, as dificuldades para alimentar as fornalhas dos engenhos conduziriam a lavoura canavieira São Paulo adentro, sempre em demanda das matas, 
distanciando-se do litoral para, enfim, alcançar as regiões interioranas em que a produção viria a ser verdadeiramente expressiva.

No contexto da expansão açucareira em São Paulo, à fundamental existência de matas seguir-se-ia, ressalta a autora, a também fundamental importância de recursos hídricos em abundância - córregos, riachos - necessários à fabricação tanto de açúcar, quanto de aguardente. O movimento das moendas e o resfriamento dos alambiques exigiam a disponibilidade de água, além de que era preciso matar a sede dos animais cuja tração o engenho utilizava para mover as moendas ou que estavam destinados a transportar a cana do canavial para o engenho. A autora enumera as dificuldades com que se viam os engenhos sem disponibilidade de recursos hídricos próximos e, mais do que referendar sua importância, remete quem se dispõe a ler a obra para os desdobramentos da inexistência de água sobre o funcionamento das fazendas, o dia a dia dos engenhos, o desenvolvimento da produção.

Entretanto, para que a fazenda fosse rentável, havia outros requisitos igualmente fundamentais, os quais a autora não se exime de analisar, ainda que brevemente: o tipo de relevo, que não deveria ser acidentado para permitir o uso de carros no transporte da cana e da lenha, a disponibilidade de terras que se prestassem a servir como pastagem, bem como sua localização que, a rigor, não deveria estar próxima de engenhos vizinhos para evitar que o gado os invadisse.

As questões apontadas - importância da existência de matas e de águas, de relevo e de pastos adequados, assim como as dificuldades e prejuízos decorrentes do esgotamento de umas e da inexistência ou inadequação de outros -, questões explícitas nos documentos a situar os necessários, porém ausentes, cuidados com os recursos naturais, ganham centralidade no texto de Petrone. Não obstante a autora o faça em poucas páginas, anuncia o nexo existente entre a economia açucareira em São Paulo, o uso racional dos recursos ambientais e a imprevidência de "lavradores (...) aos quais como diz - não interessava o dia de amanhã [preocupados que estavam] em conseguir a maior produção com o mínimo de trabalho" (PETRONE, 1968, p. 81). Anuncia, dessa forma, a pertinência de uma análise capaz de avaliar o impacto da produção agrária sobre o território que a lavoura elegera ao se expandir. 
Além disso, preocupa-se, a autora, em desvendar os meandros do poder, momento em que permite às autoridades designadas para administrar São Paulo, marcar presença em seu texto. Reserva, igualmente, para o senhor de engenho, momentos da análise em que seu modo de vida, os privilégios econômicos, sociais e políticos de que era portador, seu jeito - nem sempre bem visto - de gerenciar os negócios do açúcar e o trato com a mão de obra escrava, ampliam a percepção dos interesses econômicos e políticos em jogo.

Dada a impossibilidade de transpor para estas páginas o conjunto das informações relativas a esses aspectos, vale notar, quanto aos senhores de engenho, que muitas vezes a voz das autoridades se ergueu para questionar seu desinteresse em produzir açúcar de qualidade, sua má-fé ao não purificar devidamente o açúcar vendido com antecipação e para apontar os desdobramentos dessa situação em virtude de problemas referentes, por exemplo, ao transporte e ao acondicionamento do produto para exportação. Questões nada irrelevantes que teriam impacto sobre o desempenho do açúcar produzido em São Paulo no mercado internacional e que, pode-se dizer, contribuiriam para selar seu destino para o mercado interno, bem como o destino do café como principal produto da agricultura paulista e da economia nacional. As ponderações da autora sobre a lavoura de subsistência da qual o açúcar paulista foi tributário e, para a qual reverteria seu peso em conjuntura nitidamente desfavorável a sua exportação, colocam em pauta a importância de conhecer a dinâmica do mercado interno e sua conexão com atividades de maior relevância econômica, caso da própria cafeicultura. Segmento da economia paulista não contemplado a contento, na época, no campo da pesquisa histórica e que, nas décadas posteriores, ver-se-ia abordado, inclusive, no que se refere à cultura intercalar de mantimentos junto aos pés de café.

No que tange às autoridades, é possível fazer uma síntese que harmoniza a escolha do governo de Mourão, por parte da autora, como baliza temporal inicial da pesquisa, as condições econômicas de São Paulo nesse momento e os problemas que, conforme a visão desse governador, afetavam a agricultura local.

Para a autora, o governador Mourão ao descrever a Capitania, em 1766, o faz de forma "realmente patética" (PETRONE, 1968, p. 16). A começar pelo atraso que identifica 
no que concerne à agricultura, cuja situação não seria fonte de preocupação por seus sucessores até o advento da gestão de Bernardo José de Lorena, em 1788, para ter, na década final do século XVIII, sua imagem restaurada. Restauração que Petrone atribui a medidas que Mourão, assim como Lorena haviam tomado e, ao alinhamento entre a demanda por açúcar no mercado externo e os consequentes incentivos por parte da administração local. Conjuntura, segundo a autora, em que os paulistas acabam por se mostrar convencidos de sua "vocação" (PETRONE, 1968, p. 18) para a agricultura e decididos a se dedicar "intensivamente à cultura da cana" (PETRONE, 1968, p. 18).

Conforme avança na citada descrição, Mourão mostra-se persuadido de que o referido atraso é devido, dentre outras questões, a dois "vícios (...) poderosos" que, em seu entender, "empobrecem" o povo da Capitania, vícios, esses, "a prezumpção, e a preguiça", que seu olhar inquiridor atribui à escravidão (Documentos Interessantes para a História e Costumes de São Paulo, 73, p. 88 a 95, ofício de 3 de dezembro de 1766; Documentos Interessantes para a História e Costumes de São Paulo, 33, p. 57-58, ordem circular às Câmaras de 29 de abril de 1772, apud Petrone, 1968, p. 16). O cativeiro é, em suma, responsabilizado, em sua manifestação, pelo desprezo que o "povo" devotava ao trabalho agrícola, por uma agricultura itinerante, por homens e mulheres que, segundo ele, a nada se dedicavam na maior parte do tempo, a não ser viver dos frutos da natureza e da pesca, a ficar, dia e noite, deitados ou balançando na rede (PETRONE, 1968, p. 16). Na cadência de seu discurso, faz com que Petrone tangencie um debate que, no avançar do século XIX, ultrapassaria as fronteiras do campo e encontraria acolhida no Brasil urbano: a vadiagem.

Preocupada em dar conta das questões relativas à mão de obra, Petrone irá se aproximar, no avançar da análise, das gentes que retiravam seu sustento da faina diária das fazendas e, da mesma forma, de homens e mulheres que pareciam gravitar em torno da atividade econômica principal em solo paulista. Ainda que por intermédio da "patética" (PETRONE, 1968, p. 16) descrição de Mourão, permite a esses homens e mulheres que compareçam ao texto de A lavoura canavieira..., por mais absoluta que tenha sido a escravidão. Presença instigante, vislumbrada por entre as frestas do cativeiro e que, é viável supor, acabou por inspirar contrapontos, percepções outras, na 
perspectiva da História Cultural, sobre a vivência de homens e mulheres livres em tempos de escravidão, enfim, novas leituras sobre as práticas econômicas da população não escravizada. Suposição a que dá ensejo sua convicção de que o comportamento definido por Mourão como preguiçoso, assim como o sistema de agricultura itinerante eram, "em parte, consequência da ausência de uma agricultura comercial" (PETRONE, 1968, p. 16). Em que pese Petrone adicionar aspas à palavra preguiça - quando a ela recorre mantendo-a circunscrita à voz do governador, ao retomá-la, coloca leitores e leitoras diante de certa ambiguidade: sem dúvida, a aposição de aspas mantém a palavra e seu uso pela autora restritos ao discurso de origem mas, é inegável que sua retomada, nos termos conclusivos em que é feita, deixa latente a possibilidade de que o pensamento do governador possa ter sido, de algum modo, por ela incorporado.

Sensível à condição econômica e social dos trabalhadores, em suma, ao mundo do trabalho na lavoura paulista de cana-de-açúcar, a autora, ao abordar a escravidão reconhece a importância verdadeiramente imprescindível dessa mão de obra e, interessada em aferir sua disponibilidade, lança-se ao desafio de mapear nas fontes, também a presença de indígenas, escravos ou não, nas fazendas. No afã de elucidar a rotina do trabalho na lavoura açucareira acompanha escravos e escravas, aos quais é dado alçar plano diferencial da análise, em meio ao amplo leque de atividades laborais em que se desdobrava a organização da fazenda: a produção de açúcar, de aguardente e de mantimentos, os serviços domésticos.

Entrementes, sua investigação ultrapassa esses aspectos, ao agregar elementos que a conduzem para além do eito propriamente dito, das imposições de fazendeiros e feitores ansiosos em garantir produtividade. O cotidiano de escravos e escravas no interior das fazendas explicita-se, então, em maus tratos, em castigos rigorosos, açoites, torturas em ferros aderidos a seus corpos e avança na direção de trazer à tona as condições de vida e de trabalho a que escravos e escravas se viam submetidos, não sem apontar, conforme exposto acima, contestações por parte das autoridades em relação aos senhores de engenho quanto ao tratamento dispensado à mão de obra, pautado na prevalência de abusos. 
Contestações vêm à tona durante a análise também a partir do reduto da escravidão, pois é impossível passar ao largo da circunstância de que Petrone atribui, a escravos e escravas, o status de sujeitos sociais, por mais que o faça de revés. No momento em que a análise converge para o clima de insatisfação vigente nas fazendas, para as revoltas e o despontar de quilombos, a autora coloca, diante de leitores e leitoras, escravos e escravas que não se vergavam frente a condições de trabalho e de vida mais do que insatisfatórias, ultrajantes. Passagens da análise em que identifica, em São Paulo, uma sociedade em que o temor da insubordinação a se manifestar nas senzalas acometia o conjunto da população e invadia as casas grandes a ponto de se transformar em justificativa a que recorriam os senhores desejosos de obter isenção do serviço militar (PETRONE, 1968, p. 125). Momento esse, em que se aproxima de temas que seriam caros à futura historiografia devotada aos estudos referentes à escravidão brasileira e, em particular, à resistência escrava.

Ainda assim, ao se mostrar atenta à penetração das ideias liberais nas senzalas, de asseverar que tais "fermentações políticas e sociais [ao serem] absorvidas pelos escravos, [transformavam-se] em germes de revolta, (...) não raro em elementos de luta de classes" (PETRONE, 1968, p. 121), quer no período que antecede a Independência brasileira, quer durante a vigência do Primeiro Reinado, revela-se surpresa com a expressiva repercussão das mesmas entre escravas e escravos, em suas palavras, "classe miserável e sem instrução" (PETRONE, 1968, p. 121). Nesse passo aponta que "os escravos, compreendendo mal as ideias chegadas, às vezes incompletas aos engenhos, acreditavam que surgira a hora da libertação" (PETRONE, 1968, p. 121).

Talvez possa, a leitura de A lavoura canavieira... suscitar a impressão de que as assertivas acima constituem, considerado o percurso analítico de sua autora, uma contradição ou, em livre linguagem, um ponto fora da curva. Trata-se, entretanto, de pensamento compatível com a percepção que vigorava quanto às camadas populares no meio intelectual compartilhado pela autora, uma vez que no pano de fundo de semelhantes afirmações vigorava, então, a noção de que a "maioria da população inculta e atrasada não chegava a tomar conhecimento das novas doutrinas" (COSTA, 1985, p. 27), palavras de Emília Viotti da Costa, contemporânea de Petrone, firmadas em um dos 
ensaios reunidos na obra Da Monarquia à República: momentos decisivos, escritos entre as décadas de 1960 e seguinte. Autora do mais renomado clássico sobre a escravidão brasileira, Da senzala à colônia, cuja primeira edição data de 1966, Costa faz, portanto, no ensaio apontado acima, referência às camadas populares como incapazes de compreender o novo ideário liberal, por ela considerado incompatível com a realidade brasileira, considerada, a escravidão, como o limite do liberalismo no país (COSTA, 1985, p. 27).

Entrementes, é oportuno lembrar que a percepção quanto às camadas populares encontraria um ponto de inflexão com Thompson, ao trazer o historiador da nova esquerda para o cenário das discussões historiográficas, o entendimento de que "as aspirações [das mesmas] eram válidas nos termos de sua própria experiência" (THOMPSON, 1987, p. 13). Percepção e concepção que, algum tempo depois, inverteriam, portanto, o ângulo de observação da questão.

Não sem considerar as primeiras tentativas de produzir açúcar em terras paulistas, a autora familiariza leitores e leitoras, com as transformações da vida econômica e social em São Paulo, com as instâncias da política e suas ingerências, a partir do momento em que os canaviais tornam-se um empreendimento com vistas ao mercado mundial. Decidida a dar conta dos vários aspectos em que se desdobra a história do açúcar paulista, a autora, ao transitar no interior da fazenda, ao se aproximar das lides de fazendeiros e de trabalhadores às voltas com a produção mas, também, com a sociabilidade que ela engendra, as tensões que lhe são latentes ou que se explicitam no cotidiano, revela a amplitude de sua vocação, ao transcender o que poderia ser chamado de compartimentos da história. Sentido em que A Lavoura canavieira... claramente acena para uma história de São Paulo que faz da economia seu mote principal, sem, contudo, deixar de conferir relevância à análise da sociedade da época, assim como aos indicadores que traduzem o exercício do poder.

Analisadas sempre em suas conexões com a expansão das plantações de cana, da produção de açúcar e seu impacto sobre a economia paulista, as questões acima podem ser consideradas como vislumbres, nas páginas de $A$ lavoura canavieira..., de temáticas que renovariam e enriqueceriam a pesquisa histórica. Por mais que a historiografia 
brasileira considerada clássica esteja, como afirma Barreiro, "em grande parte comprometida apenas com os grandes temas" (BARREIRO, 1995, p. 65) e - acrescento em que pese corresponder, A lavoura canavieira..., a esse paradigma, Petrone mostrava-se no interior do diálogo que a orientação tanto de Mestrado, quanto de Doutorado, suscitava com os alunos, atenta aos modelos teóricos de análise que, nos idos das décadas que se seguiram à de 1960, passavam a embasar os estudos históricos no plano internacional e no Brasil.

Não por acaso, um breve passar de olhos nos títulos de Dissertações de Mestrado e de Teses de Doutorado cuja orientação a historiadora levou a termo, entre 1971 e 1997, revela o leque de estudos inovadores - alguns anunciados em sua própria obra - que se comprometeu a orientar, propensa, sempre, a enfrentar os desafios e dificuldades inerentes a temas inéditos, a pesquisas em fontes praticamente intocadas e a novas abordagens teórico-metodológicas: trabalho escravo e processo abolicionista, imigração direcionada ao trabalho no campo, às cidades e aos núcleos coloniais, mercado externo e, também interno, produção agropecuária e industrialização, questão fundiária, história da classe operária, da infância, da mulher, da família, história do feminismo. Temas, muitos dos quais correspondem às inquietações que, a partir dos anos de 1970, resultariam na renovação de propósitos entre historiadores brasileiros, na incorporação à pesquisa histórica de fontes documentais antes sequer cogitadas, de metodologias então recentes, em síntese, em renovadas formas de conceber, compor e fundamentar as narrativas históricas.

\section{Breve conclusão}

Vejo, na atual proposta de Tempo \& Argumento, a possibilidade de deixar registradas, em dossiê alinhado aos temas que motivaram Maria Thereza Schorer Petrone, que nos deixou recentemente, a admiração e a gratidão por ter contado com sua competência como professora no Curso de Graduação em História e, acima de tudo, com sua orientação, tanto no Mestrado, quanto no Doutorado, junto ao já citado Programa de Pós-Graduação em História Econômica. 
Devo confessar, entretanto, que a motivação maior para escrever estas páginas consistiu na oportunidade de reiterar o destaque a que a historiadora, pesquisadora incansável, faz jus no rol da historiografia brasileira, para além da análise que a conduziu aos canaviais paulistas. Motivação, acompanhada da convicção de que, como afirma Barreiro, "Não é possível refazer a história do Brasil sem buscar e discutir a referência dos clássicos, sob pena de [alimentar] o paradoxo de fazer uma história sem memória" (BARREIRO, 1995, p. 59).

No conjunto da obra de Maria Thereza Schorer Petrone é inegável o destaque que merece A lavoura canavieira..., ao elucidar uma das faces do Brasil rural, país que construiu sua história alinhado ao que se convencionou chamar de divisão internacional do trabalho, ao fornecimento, no passado, de produtos primários para o mercado externo e, em cujo pano de fundo vigorava a teoria de comércio internacional formulada por Ricardo, adepto convicto do liberalismo, a denominada lei das vantagens comparativas (1996). Merecido destaque, igualmente, por sua riqueza de conteúdo, por antecipar discussões que norteariam o olhar dos historiadores futuramente, por romper com a inexistência de estudos no que tange à presença do açúcar em território paulista e, com isso, por relativizar, de certa forma, a primazia conferida às plantações de café e à própria indústria na história de São Paulo.

Se bem que este texto não faça jus à densidade da pesquisa, ao ineditismo da documentação com que a historiadora fundamenta $A$ lavoura canavieira... e alicerça sua arquitetura, vejo-me na contingência de encerrá-lo. Ao fazê-lo, retomo as dobras de capa do livro para repor, no tempo presente, as palavras de Holanda, grafadas em 1968, e com ele concluir que a obra "verdadeiramente (...) pioneira" (HOLANDA, 1968, in: PETRONE, 1968, dobra da primeira capa) não pode ser ignorada por quem demonstre interesse em estudar a economia paulista no período analisado pela autora, assim como "suas projeções em numerosos setores da vida brasileira de ontem e de hoje" (HOLANDA, 1968, in: PETRONE, 1968, dobra da segunda capa). Recomendação que, certamente, se mantém válida neste início de anos 2000, a referendar, após mais de cinco décadas, a importância de apreciar e, se for o caso, de reapreciar a obra. Afinal, é impossível não reconhecê-la como um dos clássicos da historiografia brasileira da década de 1960. 


\section{Referências}

BARREIRO, José Carlos. E. P. Thompson e a historiografia brasileira: revisões críticas e projeções. Projeto História: Revista do Programa de Estudos Pós-Graduados em História e do Departamento de História da PUC-SP, São Paulo, n. 12, p. 57-75, out.1995.

CALVINO, Italo. Por que ler os clássicos. São Paulo: Editora Schwarcz Ltda., 2009.

COSTA, Emília Viotti da. Da Monarquia à República: momentos decisivos. 3 ed. São Paulo: Brasiliense, 1985.

COSTA, Emília Viotti da. Da senzala à colônia. 3 ed. São Paulo: Brasiliense, 1989.

HOLANDA, Sérgio Buarque de. Dobras de capa. In: PETRONE, Maria Thereza Schorer. A lavoura canavieira em São Paulo: expansão e declínio (1765-1851). São Paulo: Difusão Européia do Livro, 1968.

MOURA, Esmeralda Blanco Bolsonaro de. Apresentação. In: MOURA, Esmeralda Blanco Bolsonaro de; FERLINI, Vera Lúcia Amaral. (org.). História econômica: reflexões e construção do conhecimento. São Paulo: Alameda, 2006.

PETRONE, Maria Thereza Schorer. A lavoura canavieira em São Paulo: expansão e declínio (1765-1851). São Paulo: Difusão Européia do Livro, 1968.

PETRONE, Maria Thereza Schorer. Imigração Assalariada. In: Sérgio Buarque de Holanda. (Dir.). História geral da civilização brasileira. São Paulo: Difel, 1965. v. 2, t. III, p. 274-296.

PETRONE, Maria Thereza Schorer. $O$ imigrante e a pequena propriedade (1824-1930). São Paulo: Brasiliense, 1982.

RICARDO, David. Princípios de economia política e tributação. Trad.: Paulo Henrique Ribeiro Sandroni. São Paulo: Nova Cultural, 1996.

SILVA, Rogério Forastieri da. História da historiografia: capítulos para uma história das histórias da historiografia. Bauru, São Paulo: EDUSC, 2001.

THOMPSON, Edward Palmer. A formação da classe operária inglesa. Trad.: Denise Bottman. Rio de Janeiro: Paz e Terra, 1987. 
Recebido em 10/05/2019 Aprovado em 06/07/2019

Universidade do Estado de Santa Catarina - UDESC Programa de Pós-Graduação em História - PPGH Revista Tempo e Argumento Volume 11 - Número 28 - Ano 2019 tempoeargumento@gmail.com 